\title{
Evaluation of Phytoremediation and Bioremediation for Sandy Soil Contaminated with Petroleum Hydrocarbons
}

\author{
Amr H. Gouda, Ahmed S. El-Gendy, Taha M. Abd El-Razek, and Hesham I. El-Kassas
}

\begin{abstract}
Soil contamination with petroleum hydrocarbons causes many problems for the surrounding environment. The current research aims at studying the performance of different in-situ remediation methods for the removal of total petroleum hydrocarbons (TPH) from sandy soil at different levels of contamination. The remediation methods that were tested include phytoremediation using alfalfa, bioremediation using Pseudomonase putida, and a combination. The soil was spiked with TPH at different levels $(2.5 \%, 5.0 \%$ and $10.0 \%)$. after 90 days of experiments, the different treatments were able to reduce the level of contamination in the sandy soil with efficiencies up to a maximum of $\mathbf{9 9 . 9 \%}$ for phytoremediation, $\mathbf{9 8 . 7 \%}$ for bioremediation, and $\mathbf{9 9 . 0 \%}$ for the combination method. The experimental results showed that the TPH remediation followed the first-order kinetics.
\end{abstract}

Index Terms-Bioremediation, phytoremediation, contamination, hydrocarbon.

\section{INTRODUCTION}

Contamination of soil with petroleum hydrocarbons became a global problem due to the hazardous effects on the surrounding environment. Soil contamination with petroleum hydrocarbons takes place from many sources such as production, transportation pipelines and tankers, refineries, storage tanks, and accidents. It is now widely recognized that soil contamination with petroleum hydrocarbons is a potential threat to human health that forced the efforts in the last centuries to find efficient, low cost and environment friendly techniques for soil remediation such as Phytoremediation and bioremediation [1], [2].

Petroleum hydrocarbons degradation by Plants and microorganisms take place directly and indirectly by converting petroleum hydrocarbons into products (e.g., alcohols, acids, carbon dioxide, and water) that are generally less toxic and less persistent in the environment [3]. Phytoremediation of soils contaminated with various hydrocarbons using hybrid poplar tree can reduce concentrations of benzene, toluene, ethylbenzene, xylene, and

Manuscript received May 22, 2015; revised August 25, 2015. This work was supported in part by Pelayim Petroleum Company. Evaluation of Phytoremediation and Bioremediation for Sandy Soil Contaminated with Petroleum Hydrocarbons. Full names of authors are preferred in the author field, but are not required. Put a space between authors' initials.

A. H. Gouda is with Projects Management Department, Pelayim Petroleum Company, Cairo, Egypt (e-mail: amrhamed7777@yahoo.com).

A. S. El-Gendy is with the Department of Construction and Architectural Engineering, The American University in Cairo, New Cairo, Egypt (e-mail: elgendy03@hotmail.com).

T. M. Abd El-Razek and H. I. El-Kassas are with the Department of Environmental Basic Sciences, IESR, Ain Shams University, Cairo, Egypt (e-mail: tahaelsabbagh@yahoo.com, helkassas@hotmail.com). gasoline range organics to an average of $81 \%, 90 \%, 67 \%$, $78 \%$, and $82 \%$, respectively [1].

Bacteria are used for biodegradation of soil pollutants by removing or detoxifying that is called bioremediation technology [4]. Pseudomonas pseudoalcaligenes, Bacillus firmus, Bacillus alvei, Penicillium funiculosum, Aspergillus sydowii and Rhizopus sp. can removed 79\%, 80\%, 68\%, 86\%, $81 \%$ and $67 \%$ of TPH, respectively in 15 days experiment [5].

Very high TPH concentrations inhibit both normal germination of plant seeds and microbial activities in the contaminated soil due to the toxicity of TPH to the plant and bacteria [4]-[6]. In all contaminated cultivated soils, the reduction of crude oil was higher than non-cultivated soils, except $10 \%$ contamination level that inhibit the germination and normal growth of alfalfa [7]. Increasing of contamination levels of benzene in soil, will generally increase the duration needed for bioremediation [8]. Using phytoremediation and bioremediation methods for contaminated soil enhance the physical and chemical characteristics of the soil [2], [6], [9] Plant and bacteria can independently remove hydrocarbon from contaminated soil [9].

This work aims at evaluating the use of alfalfa, Medicago sativa L., bacteria, Pseudomonase putida, or a combination of both in the remediation of sandy soil contaminated with TPH.

\section{MATERIALS AND METHODS}

\section{A. Experimental Conditions}

All experiments were carried out in a field environment at a temperature range from $5{ }^{\circ} \mathrm{C}$ to $40{ }^{\circ} \mathrm{C}$ and an average relative humidity of $76 \%$. The indicated experimental conditions support the growth of bacteria and plants used in the study.

\section{B. Experimental Set-up}

All experiments were carried out in plastic pots. Each pot is cylindrical in shape with a diameter of $12 \mathrm{~cm}$ and a height of $11 \mathrm{~cm}$. Each pot was filled with approximately $800 \mathrm{~g}$ of soil. To study the remediation of soil at different contamination levels, the soil was spiked with three different levels of TPH contamination. Each level of contamination was subjected to four types of treatments. In the first type, Treatment 1, bacteria were added to the contaminated soil to investigate their ability in the removal of TPH from soil. In the second type, Treatment 2, plants were grown in the contaminated soil to study their ability for soil remediation. In the third type, Treatment 3, the synergic effect of using plants and the bacterial culture were investigated on the removal of TPH from the contaminated soil. The last type of treatment, Treatment 4, is the control. Control involved the use of soil without the addition of bacteria or growing plants to 
investigate the no action conditions. A blank pot (no spiking and no treatment) was also tested to determine any background contamination in the soil before spiking and any contamination that might take placed during the experimental period. In addition, alfalfa was grown in clean soil (no spiking with TPH) to monitor the plant growth in the un-contaminated soil conditions.

\section{Soil Used in the Experiments}

The soil used in the experiments was sandy soil. The soil was then spiked with petroleum hydrocarbons to reach different levels of soil contamination with TPH. These levels include $2.5 \%, 5.0 \%$ and $10.0 \%$. The soil was spiked with a solution contains TPH with $62 \%$ in the gasoline range organics (C-6 to C-12), and $27 \%$ in the diesel range organics (C-13 to C-28).

\section{Plant Used in the Experiments}

Alfalfa plant, Medicago sativa L., was used in Treatments 2 and 3 . In these two treatments, about $3 \mathrm{~g}$ of alfalfa seeds were spread on the soil surface of each pot. The seeds started to germinate from the second day after spreading on the soil surface. The percentage of seed germination was about $90 \%$. The pots containing plants were watered daily by spraying 30 $\mathrm{ml}$ of water.

\section{E. Bacteria Used in the Experiments}

The bacterial culture was prepared by isolating the selected strain of aerobic bacteria from a sandy soil sample collected from a site historical contaminated with TPH. The soil sample was collected from a location near a tank that stores petroleum product with the same TPH structure used in this experiment. Bacteria were isolated from the contaminated soil by molecular characterization method [10]. The isolated strain of bacteria includes Pseudomonase putida. A solution that contains the isolated strains was prepared with a bacterial culture concentration of $10^{8} \mathrm{CFU}$ per gram of solution. The soils in Treatments 1 and 3 were spiked with $100 \mathrm{~mL}$ of the bacterial solution.

\section{F. Sample Analyses}

To evaluate the performance of each remediation technique, soil samples were collected from pots throughout the experiment after 15, 30, 60, and 90 days. This is in addition to the samples collected at the beginning of the experiments. Samples were analyzed for TPH according to U.S. EPA, 1998 (Method 9071B) [11]. At the indicated times, pots of different treatments at different levels of contamination were taken out from the experimental set up. Then, the soil of each pot was well mixed before sampling. About $5 \mathrm{~g}$ of well mixed soil were sampled for TPH analysis. Each sample was subjected to continuous washing with $90 \mathrm{ml}$ of hexane through Soxhlet apparatus to extract the TPH from the soil sample. About $3 \mathrm{ml}$ of the extract was added to a vial with a Teflon cap for injection into a Gas Chromatography (Hewlett Packard GC, model 5890, series equipped with flame ionization detector).

\section{RESUlTS AND DisCUSSION}

Experiments were conducted to investigate the remediation of soil at different contamination levels during 90 days. The remediation includes four different treatments as indicated before. The soil was analyzed throughout the experiments to evaluate the effect of different treatments on the TPH removal as well as determining the removal rate kinetics. Fig. 1 shows the change of TPH concentration with time in soil spiked with $\mathrm{TPH}$ at $2.5 \%$ for different treatments. Fig. 2 shows the change of TPH concentration with time in soil spiked with TPH at $5 \%$ for different treatments. Fig. 3 shows the change of TPH concentration with time in soil spiked with $\mathrm{TPH}$ at $10 \%$ for different treatments.

\section{A. Evaluation of the Different Remediation Methods}

In Treatment 1, the highest removal efficiency of TPH was obtained after 90 days at all contamination levels. The highest removal efficiencies using this treatment ranged between $96.7 \%$ at the $5 \%$ contamination level and $98.7 \%$ at the $10 \%$ contamination level. Similar effect of bacterial culture in $5 \%$ diesel contaminated soils was reported; hence the observations recorded complete disappearance of n-C12-20 and $75 \%$ reduction of TPH after 42 days of bioremediation [12].

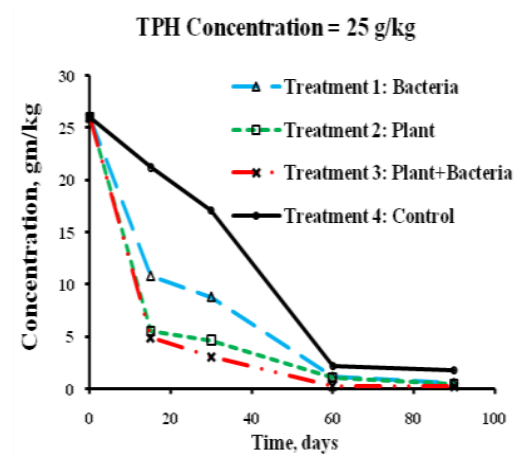

Fig. 1. TPH concentration during remediation process of hydrocarbon contaminated soils with initial contamination $2.5 \%$.

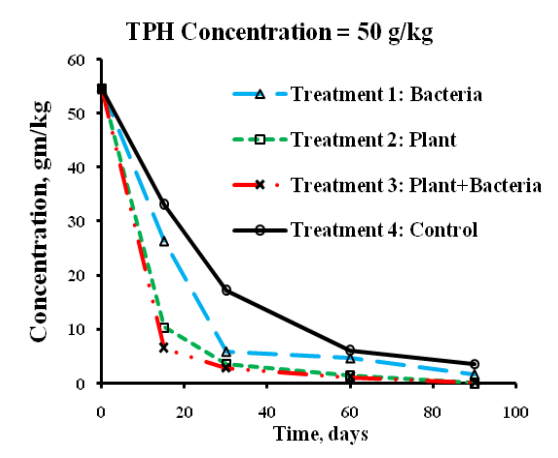

Fig. 2. TPH concentration during remediation process of hydrocarbon contaminated soils with initial contamination $5 \%$.

Similar trends were observed with other treatments. However, in Treatment 2, the removal efficiencies after 90 days ranged between $97.7 \%$ at the $10 \%$ contamination level and $99.9 \%$ at the $5 \%$ contamination level. In Treatment 3 , the synergic effect of bacteria on the removal of TPH had no significant effect on the removal efficiencies by plants. In this treatment, after 90 days, the TPH removals ranged between $98.3 \%$ at the $10 \%$ contamination level and $99.7 \%$ at the $5 \%$ contamination level.

Significant reduction of TPH contamination has been observed in control samples after the experiment period due to the environmental conditions and native microorganisms in the soil. Such significant reductions take place due to the use 
of light hydrocarbons fractions as a contaminant that have high volatility and high water solubility, this approach agreed with the findings of Alisi et al. (2009) [12] who found that the concentration of $\mathrm{C} 12$ decreased in the control sample by $65 \%$ at the end of 24 days experiment due to environmental conditions. Also Collins (2006) [13] mentioned that decreasing carbon chain length of the hydrocarbon contaminant, will increase its solubility and decrease its partition to soil, and hence increase contaminated soil remediation efficiency.

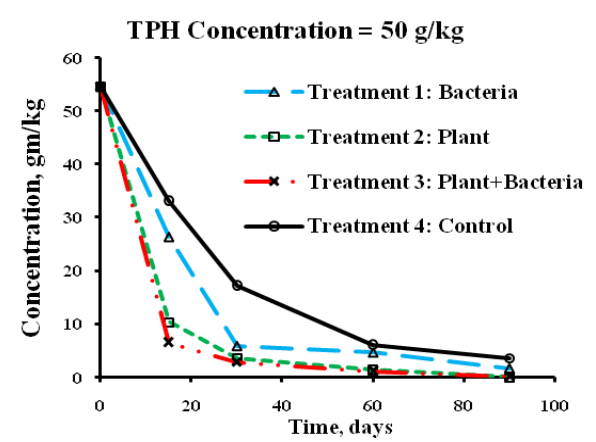

Fig. 3. TPH concentration during remediation process of hydrocarbon contaminated soils with initial contamination $10 \%$.

In general, the TPH concentration decreased with time even with controls. Fig. 1 to 3 shows that the use of Treatment 1 (bacteria) can improve the removal of TPH from the contaminated soil. This is concluded from the significant decrease in TPH concentration in soil with Treatment 1 as compared to that of Treatment 4 (control). Fig. 1 to 3 also shows that Treatment 2 (plant only) and Treatment 3 (plant + bacteria) significantly improve the remediation of soil as compared to Treatments 1 and 4 .

In general, the TPH concentration in soil decreased significantly within the first 15 days of the experiment with the use of Treatments 2 or 3 for all levels of contamination. This is compared to 30 - 60 days with other treatments. After 60 days, the changes in the remaining concentration of TPH in soil became small or insignificant. As shown in the Fig. 1 to 3, the remediation efficiencies of different treatments follow the following order in the removal of TPH; plant + bacteria $\geq$ plant only $>$ bacteria $>$ control.

However, as shown in figures, the difference between the performance with the use of Treatment 3 and Treatment 2 is insignificant. Therefore, phytoremediation using plant only (Treatment 2) can be considered as the most suitable technique to be used for the removal of TPH from sandy soil. With the use of Treatment 2, the TPH concentration in soil decreased by about $78.6 \%, 80.9 \%$, and $88.7 \%$ within the first 15 days at initial TPH contamination levels of $2.5 \%, 5.0 \%$ and $10.0 \%$ respectively.

\section{B. Kinetics of TPH Removal}

The kinetics of TPH removal using plants, bacteria and a combination was investigated. It was found that the removal of TPH in all treatments followed a first order removal kinetics. Equation 1 ahows the kinetic equation that represent the removal of TPH from soil using any of the treatments.

$$
C / C_{o}=e^{-k t}
$$

where $C$ is the TPH concentration at time $t, C_{o}$ is the initial
TPH concentration at $t=0$, and $k$ is the removal rate constant.

Results showed that the highest reaction rate constant $(k)$ was observed with Treatments 2 and 3 and its value was 0.059 day $^{-1}$ in both treatments.

\section{Mechanism of TPH Removal}

Plants and bacteria can degrade hydrocarbons contaminants from the soil directly or indirectly. Direct processes include contaminants uptake and transformation, storage, or transpiration, while indirect process is the degradation of contaminants by plant roots exudates and microbial activities [14]. In the recommended treatment, Treatment 2, alfalfa roots penetrate the soil allowing oxygen concentration to increase in soil rhizosphere. This enhances the microbial activities and population, which improves the degradation of hydrocarbons in the contaminated soil [12]. Also alfalfa increased the efficiency of hydrocarbons degradation due to the effect of root exudates such as carbon, nutrients and enzymes that enhance microbial populations in the rhizosphere [15]. In Treatment 1 (bacteria), the reduction of TPH was suggested to be due to the fact that bacteria take the hydrocarbon contaminants as a supplement for population. Bacteria take the hydrocarbon contaminants as source of carbon for new cells constituents and bacteria release enzymes in the soil, which have the ability to catalyze the oxidation of hydrocarbons contaminants [2]-[16].

\section{CONCLUSION}

Experiments were conducted to investigate the ability of different treatments in the remediation of sandy soil contaminated with different levels of TPH. Results showed that, for all treatments, the highest rate of TPH removal was during the first 15 days from the start of the remediation. After that, the removal process of TPH became slower up to day 60 . Then, no significant difference was observed for TPH removal till the end of the experiments. Results also showed that there is no significant difference in the performance of phytoremediation using plant only and using Plant-bacteria combination in the removal of TPH. The remediation efficiencies of different treatments follow the following order in the removal of TPH; alfalfa plant + Pseudomonase putida bacteria $\geq$ alfalfa plant only $>$ Pseudomonase putida bacteria $>$ control.

Overall, Phytoremediation using alfalfa is recommended for use in remediation of sandy soil contaminated with TPH with levels up to $10 \%$. With the application of phytoremediation, most of TPH is removed within the first 15 days from the start of the remediation. After 60 days, the alfalfa will have a very small effect on the removal of TPH from the contaminated soil. In addition, the kinetics study of the data obtained from the experiments showed that TPH removal followed first-order kinetics with a rate constant $k$ of 0.059 day $^{-1}$. After 90 days of remediation, the removal of TPH can reach up to $99.9 \%$ when phytoremediation with alfalfa is employed.

\section{ACKNOWLEDGEMENTS}

The authors would like to acknowledge the contribution and assistance of the personnel in Belayim Petroleum 
Company at Port-Fouad Gas Fields, Port-Said who helped in producing this research work.

\section{REFERENCES}

[1] A. S. El-Gendy, S. Svingos, D. Brice, J. H. Garretson, and J. Schnoor, "Assessments of the efficacy of a long-term application of a phytoremediation system using hybrid poplar trees at former oil tank farm sites," Water Environ. Res., vol. 81 no, 5, pp. 486-498, 2009.

[2] T. Langenbach, "Persistence and bioaccumulation of persistent organic pollutants (POPs)," in Applied Bioremediation: Active and Passive Approaches, Y. B. Patil and P. Rao, ed., 2013, Publisher: InTech, vol. 394, pp. 307-332.

[3] J. B. Eweis, S. J. Ergas, D. P. Y. Chang, and E. D. Schroeder, Bioremediation Principles, McGraw-Hill, Inc., 1998.

[4] J. Tang, R. Wang, X. Niu, M. Wang, and Q. Zhou, "Characterization of the rhizoremediation of petroleum contaminated soil: Affected by different influencing factors," Biogeosciences Discussion, vol. 7, pp. 3961-3969, 2010.

[5] M. E. Mancera-López et al., "Fungi and bacteria isolated from two highly polluted soils for hydrocarbon degradation," Acta Chim. Slov., vol. 54, pp. 201-209, 2007.

[6] U.S. EPA. "Using phytoremediation to clean up sites," U.S. Environmental Protection Agency, vol. 732, pp. 321-6751, 2012.

[7] M. H. Shahriari, G. S. Firoozabadi, M. Azizi, F. Kalantari, and D. M. Tehrani, "Study of growth and germination of Medicago sativa (Alfalfa) in light crude oil-contaminated soil," Research Journal of Agriculture and Biological Sciences, vol. 3, no. 1, pp. 46-51, 2007.

[8] A. Soares et al., "Remediation of soils combining soil vapor extraction and bioremediation: Benzene," Chemosphere, vol. 80, pp. 823-828, 2010.

[9] G. U. Chibuike and S. C. Obiora, "Bioremediation of hydrocarbon-polluted soils for improved crop performance," International Journal of Environmental Sciences, vol. 4, no. 5, pp. 223-239, 2013.

[10] K. Jyothi, K. S. Babu, N. K. Clara, and A. Kashyap, "Identification and isolation of hydrocarbon degrading bacteria by molecular characterization," BioAxis DNA Research Centre (P) Ltd, Hyderabad, Helix, vol. 2, pp. 105-111, 2012.
[11] U.S. EPA, "n-hexane extractable material (HEM) for sludge, sediment, and solid samples," U.S. Environmental Protection Agency, EPA METHOD-9071B, 1998, Revision 2.

[12] C. Alisi, R. Musella, F. Tasso, C. Ubaldi, S. Manzo, C. Cremisini, and A. R. Sprocati, "Bioremediation of diesel oil in a co-contaminated soil by bioaugmentation with a microbial formula tailored with native strains selected for heavy metals resistance," The Science of the Total Environment, vol. 409, pp. 3024-3032, 2009.

[13] C. D. Collins, "Implementing phytoremediation of petroleum hydrocarbons," Methods in Biotechnology, NJ: Humana Press Inc., 2006, pp. 99-108.

[14] S. L. Hutchinson, "Biodegradation of petroleum hydrocarbons in the rhizosphere," Phytoremediation: Transformation and Control of Contaminants, NJ: Wiley-Interscience, Inc., 2003.

[15] J. L. Kirk, J. N. Klironomos, H. Lee, and J. T. Trevors, "The effects of perennial ryegrass and alfalfa on microbial abundance and diversity in petroleum contaminated soil," Environmental Pollution, vol. 133, pp. 455-465, 2005.

[16] B. Thapa, A. K. Kumar, and A. Ghimire, "A review on bioremediation of petroleum hydrocarbon contaminants in soil," Kathmandu University Journal of Science, vol. 1, pp. 164-170, 2012.

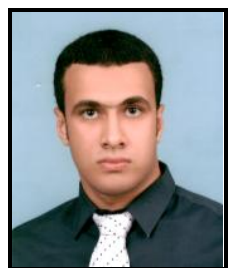

Amr Gouda was born in Egypt, 1984. He graduated from Shoubra Faculty of Engineering, Banha University, Egypt, in 2006. After that, he studied a diploma in environmental engineering from IESR, Ain Shams University, Egypt, in 2008. In 2014 he got a master of science from IESR, Ain Shams University, the Department of Environmental Engineering Science; his master thesis was in oil spill field under title of "Remediation of soil contaminated with petroleum hydrocarbons". He participated as a paper author in $6^{\text {th }}$ international conference on chemical, biological and environmental engineering, Paris, France, 2014.

$\mathrm{He}$ works as a projects engineer for Pelayim Petroleum Company (BETROBEL), which is an Egyptian company. The work responsibilities was a mechanical projects engineer (from 2006 to 2010), a planner (from 2010 to 2011) and a senior projects engineer (from 2011 up to the time being). 